\title{
The Philosophy of the Blast Smelting: Cognition and Development of the Technology
}

\author{
Tovarovskiy Iosif Grigorevich \\ Iron and Steel Institute National Academy of Science of Ukraine, Dnepr, Ukraine
}

\section{Email address:}

tovarovskiy@mail.ru

\section{To cite this article:}

Tovarovskiy Iosif Grigorevich. The Philosophy of the Blast Smelting: Cognition and Development of the Technology. Science Journal of Energy Engineering. Vol. 5, No. 1, 2017, pp. 31-39. doi: 10.11648/j.sjee.20170501.13

Received: December 27, 2016; Accepted: January 24, 2017; Published: February 23, 2017

\begin{abstract}
Based on the analysis of system properties of the blast furnace smelting identified its features as a large system and principles of construction of mathematical models to summarize knowledge about the processes and forecast of characteristics of the blast smelting. For real blast furnaces on influence the model obtained adequate results. Numerical investigation allowed to determine the of various factors on the processes to establish rational regimes for existing conditions and assess the prospects of transition to mini-coke and non-coke blast furnace smelting. The research revealed new patterns of course of the process of blast furnace /smelting.
\end{abstract}

Keywords: Smelting Parameters, System Properties, Mathematical Model, Temperature Field of the Furnace, Forecast, Mini-Coke Regime, Non-coke Technology

\section{Introduction}

One of the forms of social consciousness - philosophy is the science of the most General laws of development of nature, society and thinking, and in relation to a particular subject reflects methodological principles of formation and a meaningful framework for its development.

By the early nineteenth century advances in science have allowed, and the practical needs of the industry claimed to direct the efforts of engineers and scientists focused on the cognition and the development of the theory of the blast smelting as a basis for technical progress [1-5]. The subsequent period of broad implementation of this process showed the necessity of its generalization, which at this stage is performed at the Iron and Steel Institute National Academy of Science of Ukraine in the form of successively held international symposia with the participation of leading experts and a wide discussion of the problems $[6,7]$.

Problems cognition processes and developing technology for blast-furnace production are considered in detail by the participants of the Symposium on directions and generalized in the present work, which also includes the problems of systematic analysis, principles of operation, modeling, and forecasting. The said complex, as described below, the problems of obtaining new knowledge are designated as "the philosophy of the blast smelting".

\section{A Systematic Approach and System Properties}

The traditional approach to the analysis of the blast furnace based on detailed investigation of individual phenomena (heat and mass transfer. etc.) and then use the discovered patterns to determine the possible and desirable trends in the development of processes and management. This approach is fruitful, however, not quite sufficient for a complete understanding of the process with a view to their improvement. This is because the blast smelting in General is not the simple aggregate of individual phenomena, but a complex function of their relationships, the nature of which the events themselves and includes properties that are not inherent in particular phenomena. These peculiarities of the processes of the blast furnace allow to characterize it as a large system in modern understanding, including new concepts, including [8]:

Integrative qualities - the qualities of the system as a whole, but not peculiar to its elements separately. The properties of the system, although dependent on properties of its elements, but not completely determined by them. 
In view of the above in the study of metallurgical technologies and their development requires the use of the ideology of the system approach as methodological basis of study of large systems.

Problems of cognition the actual process of the blast smelting is still not intended as an independent and generated by the accumulation of empirical material, and a certain degree of its comprehension. At this stage there was a need of understanding the process to make it more dynamic. The basis of understanding of the process of cognition can be the analysis of its evolution (according to G.W.F.Hegel) and considering some General principles in blast smelting.

\section{System Principles}

The first of them was formulated by M. A. Pavlov [2], summarizing the position expressed earlier by R. Okerman [3], in relation to the process of heat absorption. In our broader interpretation with justification for all other processes it is expressed as the principle of attenuation [4]: the Maximum effect of the application of each measures to improve the blast furnace is achieved under conditions opposite to those leading on this event. It is complemented by the principle of combination: the Most effective combination of activities that affect essential processes in the furnace in opposite directions.

Considered two principles cover the blast melting as a simple collection of phenomena, but do not consider unity as a large system in which relationships between elements are not less important than the elements themselves, and the system includes properties that are not inherent in its individual elements. The improvement of such systems, the number of complex parameters closer to the ultimate state regardless of influencing factors. In blast smelting, in particular, decreases the residence time of the materials in the furnace, reduces the amount of gases per unit of materials, increasing the intensity of filtration of the melt through the nozzle of the coke, thereby reducing the stability of the course of processes and complicates the management. Formally, this translates into reducing the entropy of the system. A systematic approach to blast furnace smelting allows us to formulate the principle of limiting regimes:

With the improvement of technology the blast furnace and its approach to some limiting regime, the effectiveness of the entire set of measures for its further improvement is reduced.

In addition to the above, blast smelting has a number of system properties which are designated below in General form:

\section{System Properties}

Any energy imbalance that occurs in the input or intermediate stages of melting, stretched in time and does not output the final state of the specified limits (ADAPTABILITY).

Because of the uneven distribution of the medium and its properties in the unit volume of each mode contains components not relevant average parameters and deforming over time average parameters and indicators of melting by the accumulation of new properties, stimulating the spontaneous shift of the status of processes in other area and require an adjustment mode to achieve the specified performance (SPONTANEOUS SHIFTS).

Each step of cognition $(\mathrm{C} 1, \mathrm{C} 2, \mathrm{C} 3 \ldots)$ is a precondition of development (D1, D2, D3...), and the next step of development - an incentive to further knowledge (D2, $\mathrm{D} 3, \ldots)$. The result is a multivariable dynamic system (MDS).

Thus, at the present stage of study of the blast furnace we go from knowledge of individual processes to the knowledge of its system properties. This will allow not only a better understanding of the regularities of the system "blast smelting", but to create the preconditions for forecasting the further development of technology. In this way, the importance becomes a method of cognition.

\section{Methods of Cognition the Processes of Blast Smelting (Bs)}

By the mid-19th century the study of the processes of the $\mathrm{BM}$ acquired an independent value. In the subsequent half century on the basis of use of achievements of fundamental Sciences and numerous experimental studies in laboratories and blast furnaces created a system of knowledge suitable for practical use, the significance of which received a vivid description of L. Boltzmann: "there is Nothing more practical than a good theory".

By the end of the twentieth century has accumulated a large amount of knowledge, some of which are repeats of each other, while others are contrary to the results of similar studies. The explanation of the results with the same positions all the more difficult. This is due to the fact, that the accumulation of knowledge was ahead of their systematization at the present level, namely the creation of a workable mathematical model of the blast furnace process, on the basis of which possible generalization and prediction.

Among the methods of cognition of natural phenomena mathematical modeling occupies a special place. It allows you to penetrate deeper into the essence of phenomena, to better understand the relationship of processes and on this basis to form forecasts. The fruitfulness of the correct use of mathematical methods in various fields of scientific knowledge was noted by many outstanding scientists: Leonardo da Vinci., I. Kant, M. Bourne, George von Neumann.

Thus the correct use of mathematical methods is complicated by the need for a deep understanding of the subject essence of the phenomena and the intricacies of the mathematical apparatus and characteristics of system analysis processes. Since this approach is not available to many researchers, a number of eminent scientists have considered the problem of skepticism, and sometimes with irony:

Since then, as for the theory of relativity began math, I already did more, don't understand... There is an amazing 
opportunity to master the subject mathematically, not understanding the merits of the case. A. Einstein.

The most perfect model of a cat is a cat, but better himself. N. Wiener

Thus, the use of subtle and effective means of cognition of the processes of mathematical modeling requires a deep understanding of the essence of the phenomena and their formalization with the use of well-chosen mathematical apparatus. Numerical solution of the problem and the presentation of results should enable a substantive analysis of not only output but also the intermediate parameters and their relationships. Given the impossibility of achieving the complete adequacy of the model to the real process (see, e.g., comment N. Wiener above), the nature of model construction (e.g., modular) needs to be adjustment and additions as the verification of the adequacy of the real processes in a wide range of modes. This approach does not always meet the possibility of applying classical methods of modeling and the use of known methods of numerical solution. However, the priority of this approach is the meaningful interpretation of the results dictates the need to find innovative solutions in terms of modeling and finding numerical results in order to preserve the objectivity of the results (see A. Einstein).

In blast melting process the adequacy of models of real processes depends mainly on the degree of scrutiny processes.

Using the results of experimental researches of blast furnaces in the synthesis of theoretical knowledge about the processes significantly promote the development of a comprehensive model of the blast furnace, and the most significant results obtained by the Japanese and Russian developers. The results illustrate the possibility of wide use of models for the analysis of real technologies and development of new technological solutions. To date, however, such a large-scale analysis of any model are not carried out. The reasons for this are due not only to the difficulties of rethinking technology as a whole system, but also those that require a specific construction of models for ease of handling them in the course of analytical studies.

Setting himself the task of overcoming these difficulties, the developers of ISI NASU started with creating your own model for analytical researches of processes the blast furnace. Of the models previously created by other professionals, the creation of his was due, among other things, the need to match the requirements of consistency of parametric analysis of performance processes, including the adequacy of simultaneous reflection on the possibilities of all the processes and indicators on all parameters. Only when using this model it is possible to identify certain regularities traditionally drop out of attention of researchers remain outside the analysis. The above regularities after checking on real objects can serve a basis for deepening of insights and development of new technological solutions.

Developed in the ISI NASU mathematical model is characterized in that on the basis of the structural linkage of multiband height and radius of the blast furnace and General balance of mass and heat increased the predictive power of the model, including by establishing new quantitative relationships of the processes and identifying the influence of the uneven distribution of materials for furnace radius on the performance of melting. In addition to the quantitative clarification of the relations of the initial parameters and final results (coke consumption, productivity), revealed the internal communication processes in the furnace volume (including some new) that affect the character of the smelting regimes and the final results. Along with the balance factor of coke saving in determining the basic amount of decrease of heat consumption, the calculations take into account and evaluated a significant influence on the coke consumption of the nature of heat and mass transfer, phase transformations, gas-mechanic and distribution of materials and gases in a furnace, connected direct and feedback with the coke consumption.

The new approach opened up additional possibilities for the analysis of processes and generation of measures to improve the efficiency of the smelting, including the limiting detection zone height and the cross section of the furnace.

\section{Forecast of Indicators and Assessment of Processes}

Using the developed model based on the performance indicators of $\mathrm{BF}$ № 9 OJSC "AMKR" one of the characteristic periods performed a comprehensive analytical study of blast furnace processes, including multivariate calculations for processes with variation in a wide range of the actual values of the parameters of the charge injection and distribution of materials $\mathrm{o} / \mathrm{n}$ the furnace top. The latter is illustrated in Figure 1 the relative values of ore loads (OL relative to the average) radius of the furnace. Shows the distribution of three types of OL in two variants:

1) if the original terms of the English: cone cool - CC, the smooth flume - SF, flume uniform - FU.

2) if the original terms of the Russian: $\mathrm{KKp}=\mathrm{CC}$ ЛПл=SF $Л \mathrm{P}=\mathrm{FU}$

Study on the influence of the input parameters of melting on the formation of temperature-concentration and phase fields of BF showed significant quantitative differences for different parameters: the most powerful, along with the distribution of materials was the influence of preliminary metallization of the charge, consumption of natural (coke oven) gas, oxygen and blast temperature; other parameters influence is weaker. The studies revealed some new regularities of the processes of melting: 1) a variety of schemes of heat transfer along the height of the radial zones, up to the degeneracy of the upper level heat transfer or transformation temperature field $\mathrm{BF}$ in the direction of the scheme inherent in the cupola furnace; 2) a minimum radius, the development of direct reduction of iron from the periphery; 3) the flow of gases in the radial direction at different horizons; 4) a complex system of forward and backward linkages of the parameters of the zone of softening 
and melting (SMZ) with a set of input, intermediate and output parameters; 5) same for heat removal from the walls of the furnace.

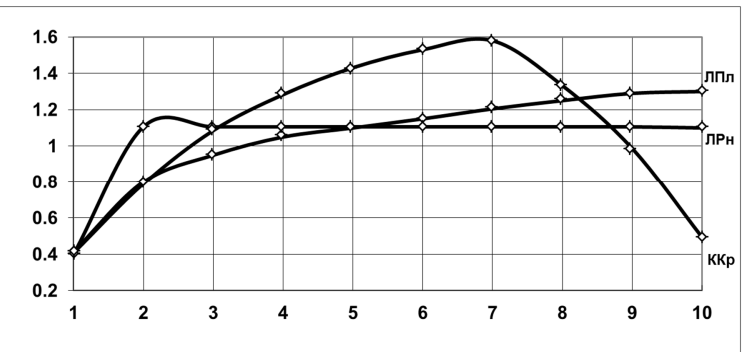

Figure 1. Relative load ore $R N$ on the top (ore load vertically) in the vertical annular zone number 1-10 (horizontal) for three variants of the ore load distributions: $K K p=C C$, ЛПл=SF, ЛP $=F U$.

Analysis of the modes of the BF showed:
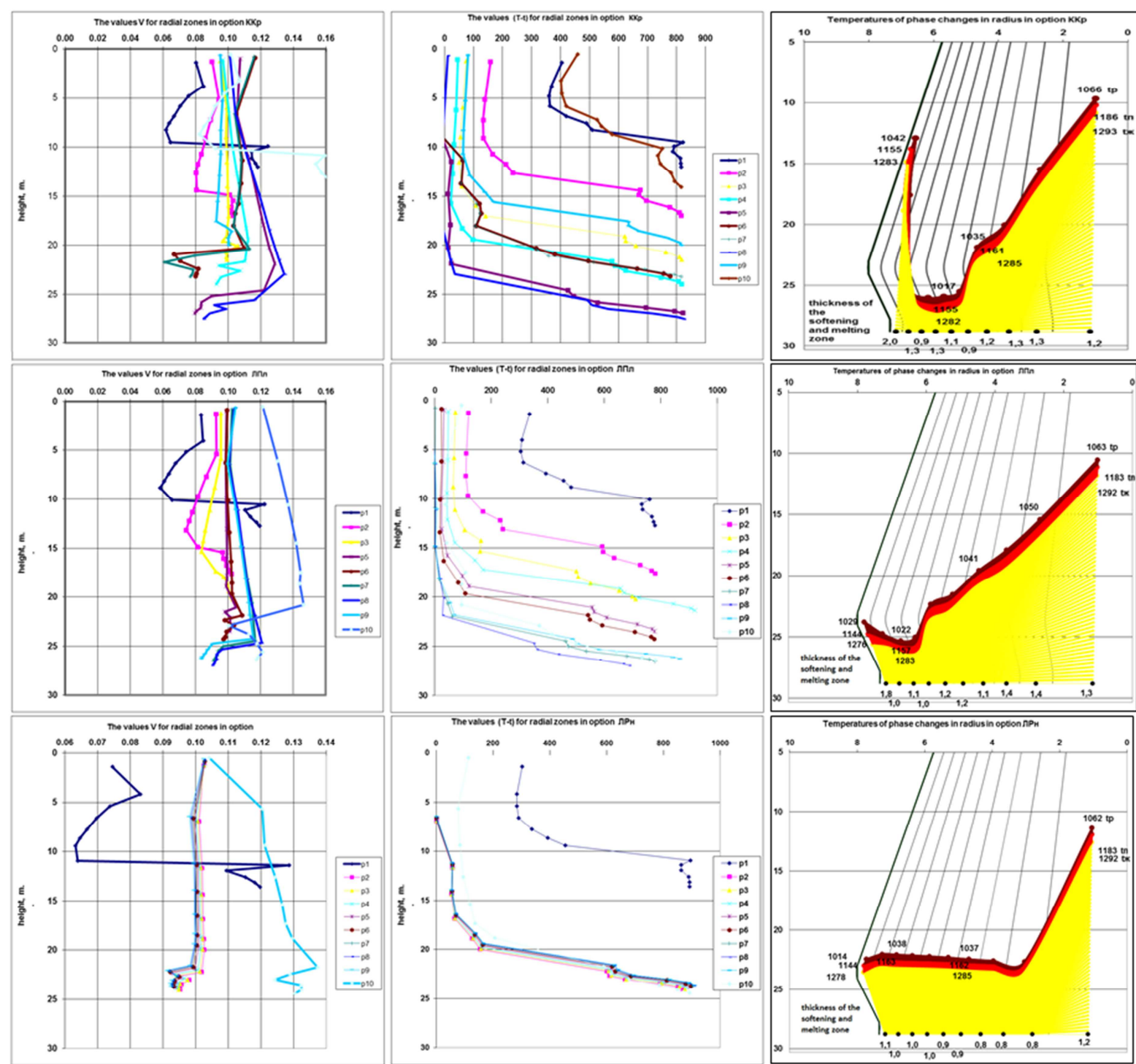

Figure 2. The amount of gas in the radial annular zones RAZ-1-10 ( $\mathrm{V}$ - the proportion relative to the total-graphics on the left); the temperature difference between the gas and burden (T-t) - in central; parameters of softening and melting zone (ZSM - on right) for the three variants of distribution of the ore load on the top: ККp (the first row of graphs), ЛПл (second row), ЛРн (third row); parameters softening and melting zone on the radius of the furnace at different heights (the vertical distance from the top, $m$ ) for three variants of the relative distribution of the ore load (vertically) in RAZ-1-10 (from the horizontal axis, $m$ ). $t_{p}, t_{n,}, t_{ж}$-temperatures softening point (brown), melting (red) and liquefaction (yellow), respectively.
The uneven distribution of materials and gases in 12 vertical temperature zones (VTZ) in height and 10 radial annual zones (RAZ) radius of the blast furnace determines the corresponding the unevenness of the processes and polymorphism of temperature-concentration phase and gasRAZ with high actual ore load is characterized by degeneration of the upper stage of heat transfer and the increased development of direct reduction, leading to a shortage of heat in high temperature VTZ and the corresponding increase in total demand of heat and the weakens this process and the concentration field is influenced by processes in the zone of softening and melting (SMZ) gas flow "wraps around" the SMZ through the "vents". dynamic fields in the furnace volume. At the same time for consumption of coke. The redistribution of the OL - radius,

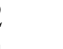




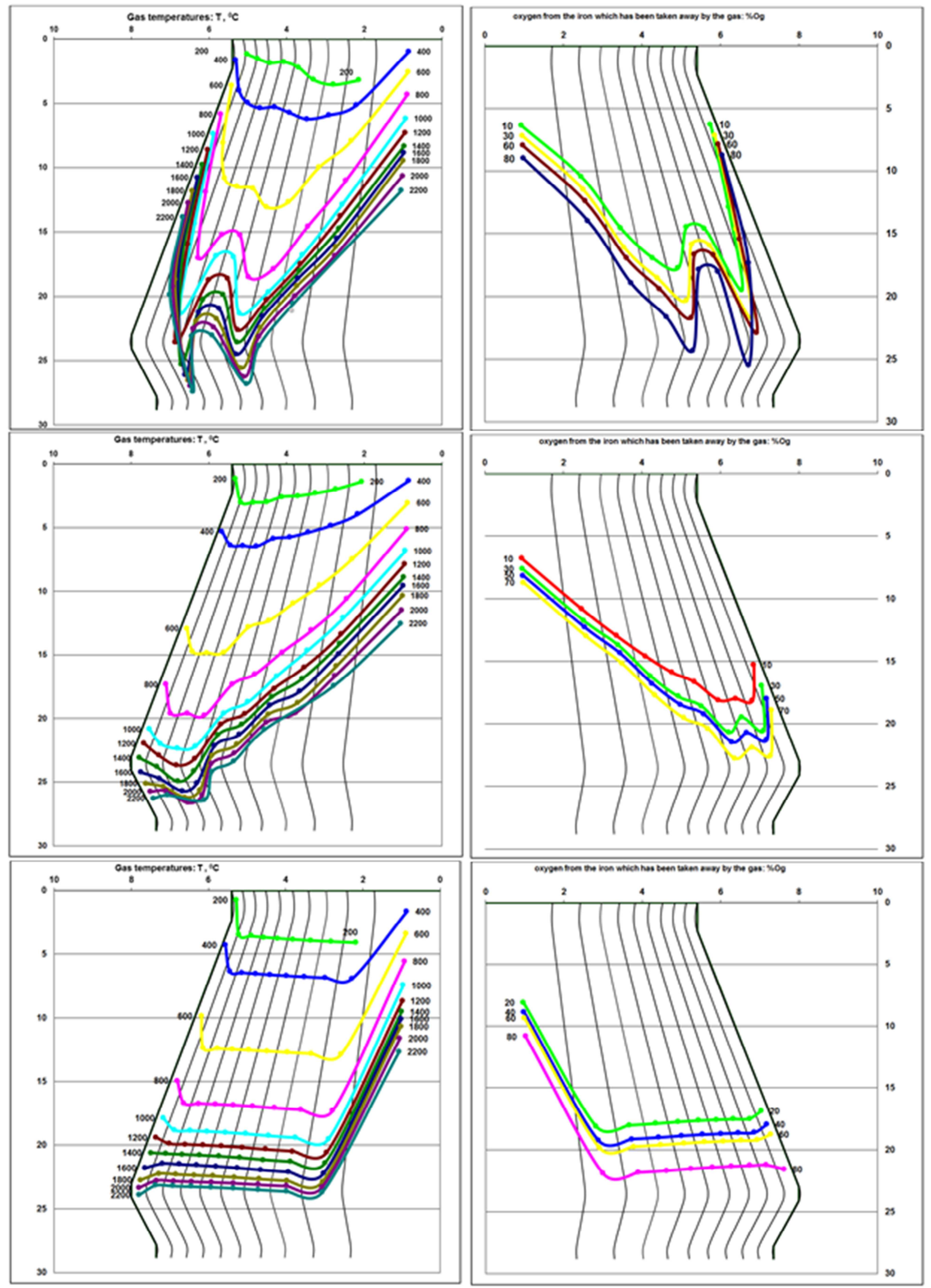

Figure 3. The isotherms of gas and contour lines of the amount taken away oxygen gas from the burden into working space of the blast furnace. Horizontal the distance from the axis, $m$ Vertical - the distance from the furnace top. 
The backflow furnace gas is a single coherent system of movement of the batch and gas in conjunction with the products of their interaction, phase transitions and energy exchange. The movement of gas occurs not only vertically. The most complex trajectories have the axial and peripheral flows, particularly in the area of "wrapping" the SMZ (Figure 2). In RAZ-10 (periphery) is observed at 20-25 m, rRAZ-1 (axis) is 7-10 $\mathrm{m}$. Above the zone of flow is the outflow of gas from the periphery and axis in the intermediate RAZ-2-9 reduction of amount of gas in the RAZ-1 in 1.5-2 times (up to $0.06 \mathrm{~m}^{3} / \mathrm{m}^{3}$ ) and the change in the composition, including the expense of taking away oxygen from the charge and transporting in vertical and horizontal directions. Contours of the temperature difference $(\mathrm{T}-\mathrm{t})$ in combination with gas isotherms (Figure 3) illustrate the temperature field of the BF in conjunction with these factors, and the inflection of the curves at the minimum value of (T-t) denotes the position of the boundaries of the zones of heat transfer for each of the 10 RAZ (from 5 to $20 \mathrm{~m}$ ). The concentration field is influenced by the amount taken from the batch of oxygen and form mirrors that of the temperature field (Figure 3).

The maximum development of direct reduction often takes place in the RAZ-1 (Central) and 30-50\% under the average for furnace $20-40 \%$; the minimum is achieved in RAZ-10 (peripheral) is $3-15 \%$. In the transition to the uniform distribution of the OL of the leveling values of the degree of direct reduction in the $-2-9$ and most often a decrease in the degree of direct reduction in RAZ-1 and 10 ..
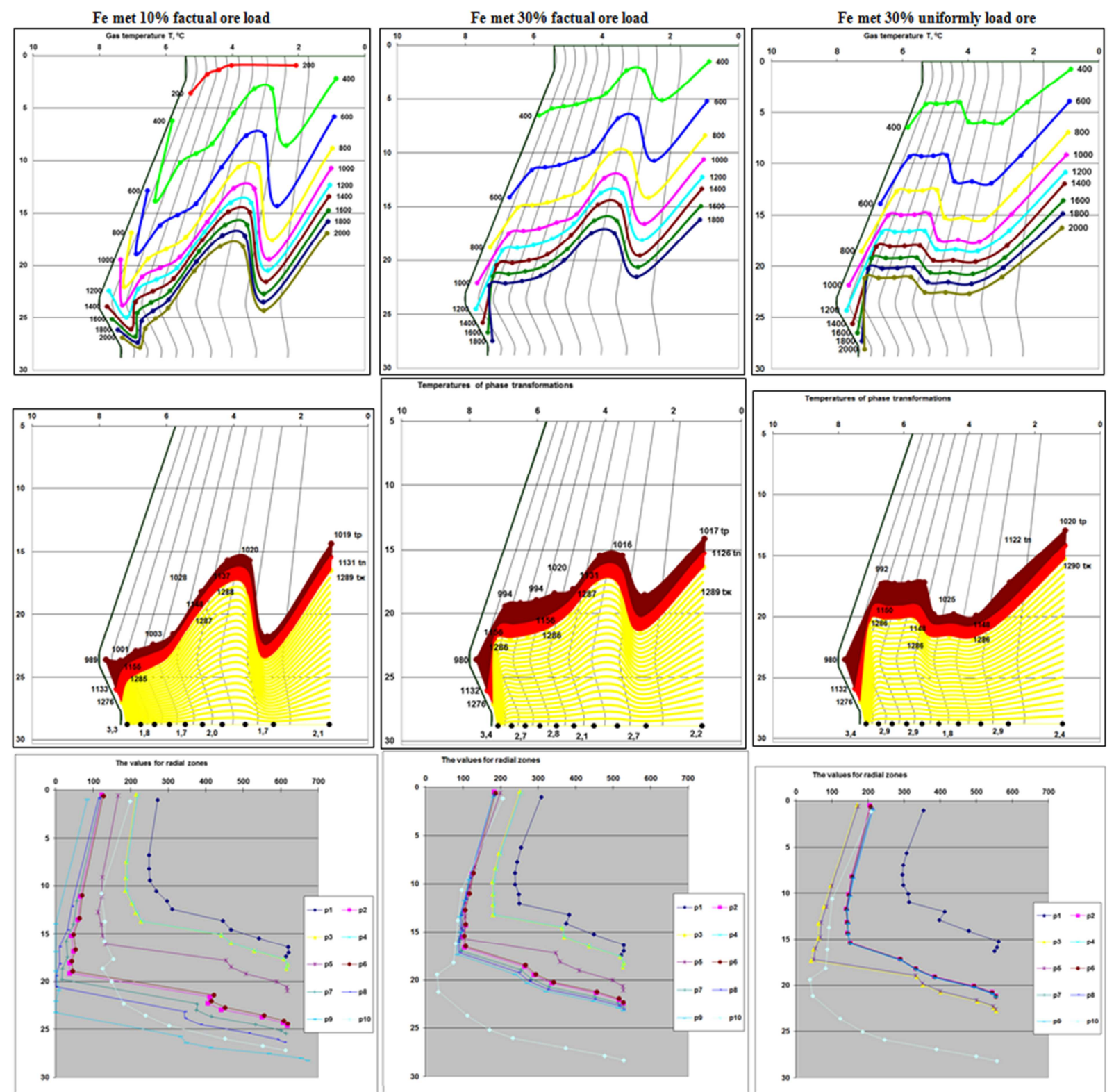

Figure 4. - The isotherms of gas (top graphics); softening and melting zone (average graphics); the difference between the gas temperature and the burden T-t (bottom graphics) in the volume of BF-9 ArcelorMittal Krivoy Rog"(RAZ p1-p10) with varying degrees of pre-metallization of burden. Vertical: the distance from the top of the furnace, $m$. Horizontal: distance from the center of the furnace, $m$ (upper and middle graphs); the difference between the gas temperature and burden (lower graph). 

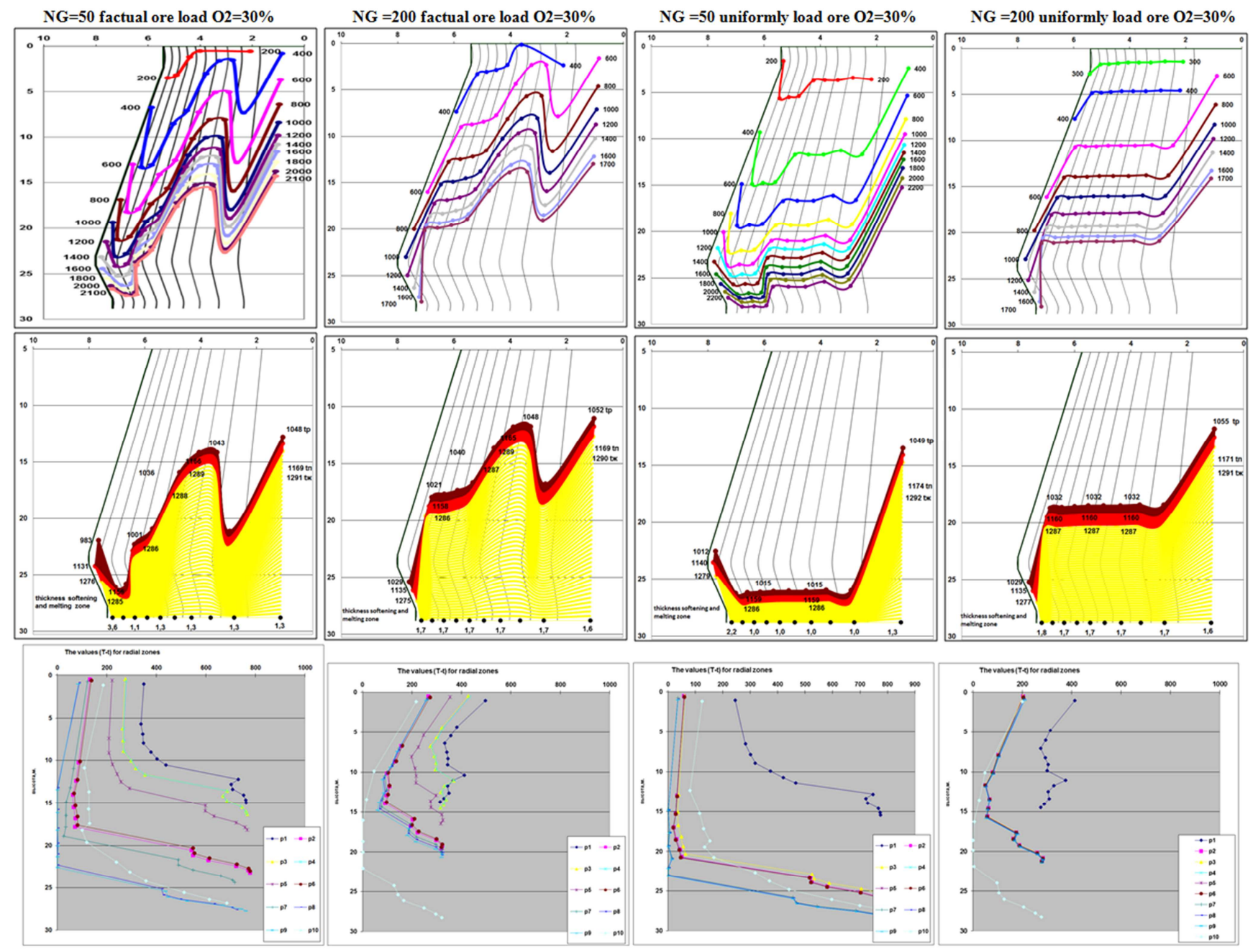

Figure 5. - The isotherms of gas (top graphics); softening and melting zone (average graphics); the difference between the gas temperature and the burden T-t (bottom graphics) in the volume of BF-9 ArcelorMittal Krivoy Rog"(RAZ p1-p10) at various flow rates of natural gas and blast content in $30 \% \mathrm{O}_{2}$. Vertical: the distance from the top of the furnace, $m$. Horizontal: distance from the center of the furnace, $m$ (upper and middle graphs); temperature difference between gas and the burden T-t (lower graphs).

Organically inherent in the cone of the boot devices (cbd) parabolic distribution of ore loads characterized by high values of OL to $2-3$ RAZ intermediate and significantly different from the distribution of OL when loading a bell-less device (bld), providing a more uniform distribution of OL. This allowed on the basis of the approach is first to estimate by calculation (using the model) the expected reduction in coke consumption when using the bld insted cbd.

Radical process changes occur with increasing degree of preliminary metallization of the charge reduces the heat load on the direct reduction of iron and, accordingly, decreases the specific heat igratio of the mixture and gas, as well as the intensity of heat transfer in the lower zone (Figure 4). This increases the need for heating the products of smelting height of the bottom step of heat exchange and consequently reduced the height of the upper if you increase the minimal height difference, and temperature of the charge and gas. The result is gas isotherms move upwards, increasing the losses through the furnace top, and the area of softening and melting points will be above the base position and thickens (Figure 4). Under the influence of these phenomena the main balance factor of coke saving from the use of pre-metallized charge cannot be implemented adequately if the degree of metallization of more than $20 \%$ because the heat and mass transfer processes, phase transformations and gas-dynamic develop in the direction of limiting the effectiveness of the implementation of this technology (Figure 4)

The most important characteristic of the flow rate of natural gas (NG): reduces the heat load on the direct reduction of iron and, accordingly, decreases the specific heat ratio of the mixture and gas, as well as the intensity of heat transfer in the area while increasing it in the upper area (Figure 5). As a result, the increase in the consumption of $\mathrm{NG}$ to $100 \mathrm{~m}^{3} / \mathrm{t}$ cog. the equivalent of coke substitution (ECS) is about $0.8-0.9 \mathrm{~kg} / \mathrm{m}^{3}$, with a further increase in the flow of GHGs and the reduction degree of direct reduced to $\mathrm{rd}<20 \%$ there is a sharp increase of the temperature of the flue gas, leading to a reduction ECS in 1.5-4 times.

The General direction of the deformation of the temperature field of the gas flow with increasing flow rate $\mathrm{PG}$ is the same as deformation using a pre-metallized charge, where there is a gradual transformation inherent in the blast 
furnace process diagram of heat transfer in the direction of the scheme inherent in the cupola (see above).

Based on the performed parametric analysis the favorable conditions for the comprehensive use of the best melting parameters and performed analytical research of indicators and processes blast furnace in terms of maximum reduction of coke consumption due to its replacement of coal $(250 \mathrm{~kg} / \mathrm{t})$ and coke oven gas $\left(100 \mathrm{~m}^{3} / \mathrm{t}\right)$ with the increase of $\mathrm{T}$ of blast up to $1300^{\circ} \mathrm{C}$ and concentration of oxygen of $25 \%$ when the content of iron in fluxed fully charge up to $60 \%$ and required improvement of the metallurgical properties of coke and raw materials and also optimizing the distribution of materials on the furnace top. Calculations the possibility of reducing coke consumption in this mode up to $190 \div 200 \mathrm{~kg} / \mathrm{t}$ cog. Taking into account the implementation of rational distribution of ore loads on the furnace top in this mode, there is a tendency to degeneration of the upper stage of heat transfer in RAZ-210 , which is amenable to inhibition by addition of coke oven gas. They meet the limit values of degrees of use of energy gases. SMZ moves down while maintaining the peripheral part RAZ -10) in the region of shoulders and Central (RAZ1) - in the middle-top of shaft.

Highly efficient technology of PCI may not be the only in the industry in connection with the shortage of high-grade coals and dynamic market conditions. Its expansion must be accompanied by the development of complementary and alternative technologies, in particular combination with the injection of coke-oven gas, products of gasification of lowgrade coals of wide application, etc., as well as a download of a specially prepared lump anthracite. The fundamental solution to the problem of reducing coke consumption to $180 \div 200 \mathrm{~kg} / \mathrm{t}$ of pig iron using its replacement of low-grade coals can be obtained on the basis of the development of new technology the blast furnace with injection of hot reducing gases - products of gasification of coals $[9,10]$ obtained in special gasifiers two types: 1) on each tuyere device blast furnace, 2) in a separate Assembly outside of the furnace.

Identification is considered and other possible patterns based on processes blast furnace in the form of a polymorphic complex temperature-concentration phase and gas-dynamic fields in the volume $\mathrm{BF}$, is discretized by 120 local volumes that are linked by a single system of material and heat balance identifying the local limiting volume. Analysis of processes on this basis avoids at least the system errors inherent in prior approaches. The prediction of the efficiency of using pre-metallized raw material with the help of the model, which postulated a value of the temperature difference between gas and burden on the border of two zones of heat transfer $<10^{\circ}$ to the furnace as a whole, gives distorted results in the analysis of this factor can be seen more clearly than with other factors.

Application to the analysis of mathematical models constructed on the basis of consistency of parametric analysis, as well as the adequacy of simultaneous reflection on the possibilities of all the processes and indicators on all parameters, not only made it possible quantitatively to assess the impact of initial parameters on the final results (coke consumption, productivity), as well as reveal the internal communication processes in the volume of the furnace (including some new) that affect the nature of the modes and results of melting, and quantitative oceanit influence on the coke consumption of the nature of heat and mass transfer, phase transformations, gas-dynamic and distribution of materials and gases in a furnace, connected direct and feedback with the coke consumption.

At the same time identified and clarified some regularities of the course of the process, some of which qualitatively confirmed the previous experimental studies. The regularities of transformation of temperature - concentration phase and gas-dynamic fields in the BF volume and cross flows of gas at high column of the charge help to explain a number of complex phenomena and can be considered as tools of selfregulation in a large system "Blast smelting", and established a complex system of forward and backward linkages of the parameters of the zone of softening and melting, and heat loss through walls with a set of input, intermediate and output parameters of the blast furnace is an important component of the system analysis of smelting.

Further study of this system is considered the method with the addition of new experimental studies will reveal new regularities of the development processes and additional system properties that can be used to improve technology. It is primarily the achievement of the lowest possible level of coke consumption, which we estimate at $180-200 \mathrm{~kg} / \mathrm{t}$ of cast iron. Decrease of coke consumption up to this level cannot be achieved only by traditional methods. One of radical ways of solution of this problem is the injection of coal gasification products developed by us based on the foundations of the technology and preforming gasifiers. Further evolution will follow the path of non-coke smelting in shaft-hearth unit on the basis of the blast furnace. In parallel to the development of the energy, sanitation and ecological functions of blast furnaces by rebuilding decommissioned by the balance of the metal aggregates in the mode of gasification of coal and disposal of waste as well as smelting of ferro-alloys. This concept of the development of metallurgy meets the evolutionary nature of progress in this industry, spaning the deep socio-economic strata of the social organism. In the final stage of this evolution creates non-coke technology of obtaining of metals in mine-hornbeam unit on the basis of the blast furnace [1]. This technology has been successfully opposed in the competition of alternative (liquid-phase reduction-LPR, COREX, ......etc.) and remains a priority for a long period, leaving place to others under certain conditions: for example, the construction of the facility LPR in the blast furnace plant in the event of an increase in the number of recyclables.

\section{Conclusion}

Based on the analysis of the evolution of blast smelting technology and process cognition identified the presence of complex systemic properties and principles of operation, which gives the system "Blast smelting" the status of the 
large system. In this status, the system behavior is complicated and depends not only on the active factors, but their combinations, relations, quantitative and qualitative characteristics. The possibility of a reliable assessment of the relationships of the parameters and indicators of the blast furnace under different conditions and the generalization of the results in the form of a mathematical model.

To implement this feature in the ISI of the NAS of Ukraine developed a mathematical model of the blast smelting (MMBS) to solve wide range of tasks of analysis and forecast performance, processes and melting regimes.

A numerical study for a wide range of parameters BS allowed us to determine the influence of various factors on the processes to establish a rational modes of BS for existing conditions and assess the prospects of transition to mini-coke and non- coke technology of BS.

The research revealed new regularities of the course of the heat: 1) variety of schemes of heat transfer along the height of the radial zones, including the degeneration of the upper stage of heat transfer; 2) a minimum development of direct reduction of iron by the periphery; 3 ) the flow of gases in the radial direction at different horizons; 4) a complex system of forward and backward of the parameters of the zone of softening and melting (SMZ) with a set of input, intermediate and output parameters; 5) same for heat removal from the walls of the blast furnace.

\section{References}

[1] M. A. Pavlov. Metallurgy of cast iron. Part 2. The blastfurnace process. - Sixth edtion. - M.: Metallurgizdat, 1949. 628 р. Павлов М. А. Металлургия чугуна. Ч. 2. Доменный процесс. - Издание шестое. - М.: Металлургиздат, 1949. $628 \mathrm{c}$.

[2] Diepschlag E. Der Hochofen. - Leipzig.: Ferlag von Otto Spamer. - 1932. В пе реводе с немецкого под редакцией A. Н. Похвиснева: Дипшляг Е. Доменный процесс. -ХарьковДнепропетровск: Гос. н-техн. изд Украины, 1935. - 352 с.

[3] Ramm A. N. Modern blast furnace process. Moscow."Metallurgy".- 1980.-304 p. Рамм А. Н. Современный доменный процесс. Москва.- «Металл.ургия».- 1980.- 304 с.
[4] Tovarovskiy I. G. Cognition processes and development of a technology for blast-furnace production // Dnepropetrovsk: "Gurfund".- 2015.- 912 р. Товаровский И. Г. Познание процессов и развитие технологии доменной плавки // Днепропетровск: изд-во «Журфонд».- 2015.- 912 с.

[5] A. Babich, D. Senk, H. W. Gudenau, K. Th. Mavrommatis IRONMAKING. RWTH Aachen University. Department of Ferrous Metallurgy. Aachen-2016.

[6] Cognition of processes of blast furnace. Collective scientific work of the international Sym-posium edited by V. I. Bolshakov and I. G. Tovarovskiy - Dnipropetrovsk.publishing house "Porogi".-2006.-440 p. Познание процессов доменной плавки. - Коллективный научный труд международного симпозиума под редакцией В. И. Большакова и И. Г. Товаровского. - Дне-пропетровск.издательство «Пороги».-2006.-440 с.

[7] Cognition the processes and development the technology of blast smelting. Collective scientific work of the Second international Symposium, edited by I. G. Tovarovskiy. Dnipropetrovsk.- publishing house "Gurfund".-2016.-382 p. Познание процессов и развитие технологии доменной плавки. - Коллективный научный труд Второго международного симпозиума под редакцией И. Г. Товаровского. - Днепропетровск.- издательство «Журфонд».-2016.-382 с.

[8] Nikolaev V. I., Bruk V. M. Systemotechnic: methods and applications.- L.: Engineering.-1985.-199p. Николаев В. И., Брук В. М. Системотехника: методы и приложения.- Л.: Машиностроение.-1985.-199 с.

[9] Tovarovskiy I. G., Merkulov A. E. Blast smelting with injection of products of coal gasification. Kiev: "Naukova Dumka" NAS of Ukraine.- 2016.- 224 р. Товаровский И. Г., Меркулов А. Е. Доменная плавка с вдуванием продуктов газификации углей. Киев: «Наукова думка» НАН Украины.- 2016.- 224 с.

[10] Theoretical and practical principles of the use of anthracite in blast furnace smelting. V. P. Lyalyuk, I. G. Tovarovskiy, D. A. Kassim, I. A. Lyakhov.- Kryvyi Rih: "Dionit".-2016.-314 p. language is Ukrainian Теоретические и практические основы использования антрацита в доменной плавке. В. П. Лялюк, И. Г. Товаровский, Д. А. Кассим, И. А. Ляхова.Кривой Рог: «Дионит».-2016.-314 с.- язык укр. 